\title{
El resarcimiento del daño inmaterial o extrapatrimonial en la jurisdicción contenciosa administrativa ${ }^{1}$
}

\section{The compensation of immaterial damage or extra-contentious administrative contentious jurisdiction}

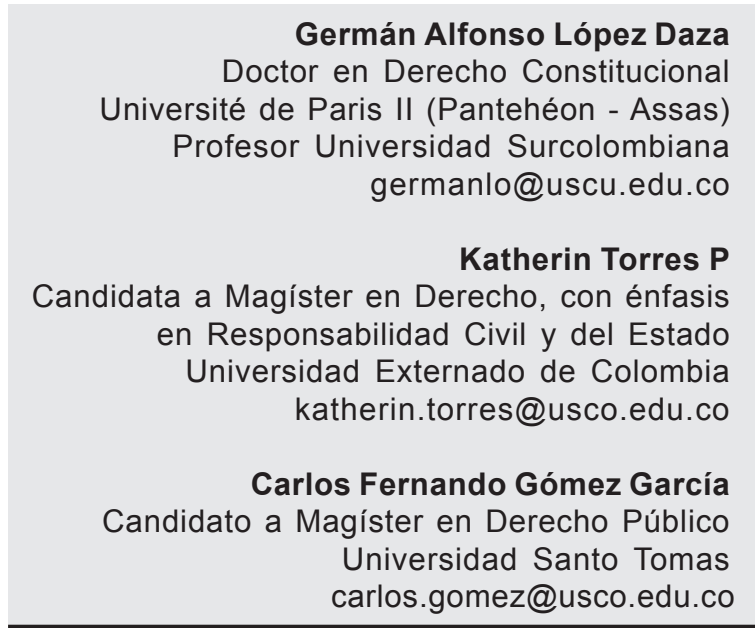

\section{RESUMEN}

En Colombia desde el siglo XX, existe la posibilidad de indemnizar pecuniariamente el daño moral como tipología distinta a los daños materiales (daño emergente y lucro cesante), situación que fue aceptada en la jurisdicción Contenciosa Administrativa; sin embargo, a partir de 1993 aparecen otras categorías del daño inmaterial, que han generado múltiples discusiones y posturas al interior del Consejo de Estado. Este artículo se ocupa de realizar una exposición de la evolución de la tipología del daño inmaterial y los criterios de cuantificación utilizados por la jurisdicción Contenciosa en los últimos trece años, realizando especial énfasis en las sentencias de unificación proferidas en el 2014, que establecieron los criterios para el reconocimiento y cuantificación de los daños antijurídicos causados por entidades públicas, decisiones que resultan vinculantes para la labor de los tribunales y juzgados de esta jurisdicción.

\section{PALABRAS CLAVE}

Daño extrapatrimonial, Consejo de Estado, Tipología, Cuantificación.

1 El presente artículo constituye uno de los resultados de la investigación denominada: «El daño moral en la jurisdicción contencioso administrativa: ¿Test de proporcionalidad o arbitrio judicial?», realizada en el año 2014 por el Grupo de Investigación Nuevas Visiones del Derecho y el semillero de Investigación Estudios Constitucionales, integrado por los estudiantes: Andrés Camilo Alvarado Esteban, Mercy Julieth Olaya, Luisa Fernanda Hernández Barrera, María Alejandra Arrieta Aviles y Juan Camilo Laverde Gaona. 


\section{ABSTRACT}

In Colombia, since the twentieth century, it is possible to monetarily compensate the moral damage, as distinct from the material damages (damages and lost profits) typology, a situation that was accepted in the administrative courts; however, since 1993 other categories of non-pecuniary damage appear, generating many discussions and positions within the Council of State. This article deals with a presentation of the evolution of the types of non-pecuniary damage and quantification standards used by the contentious jurisdiction in the last thirteen years, making special emphasis on unifying sentences handed down in 2014, which established the criteria for recognition and quantification of wrongful injury caused by public entities, decisions tied for the work of the tribunals and courts of this jurisdiction.

\section{KEY WORDS}

Pecuniary losses, the State Council, Typology, Quantification.

\section{INTRODUCCIÓN}

La existencia del daño moral, aunque reconocida, no siempre fue resarcida. En efecto, debido a consideraciones éticas y jurídicas se concebía que el dolor no tenía precio ${ }^{2}$ y que la dignidad estaba por encima de cualquier tasación pecuniaria; sin embargo, en Colombia, la Corte Suprema de Justicia con sentencia proferida en 1924 en el caso Villaveces ${ }^{3}$ ordenó por vez primera el resarcimiento del daño moral, y desde entonces, se consideró que la reparación tenía como finalidad reconocer el dolor sufrido (pretium doloris), que en ningún caso se aspira pagar, pero sí aligerar la perdida; así las cosas, el dinero apostaría también por satisfacer el sufrimiento ocasionado (Tamayo, 2007).
El desarrollo jurisprudencial ha permitido que se indemnice el daño moral en distintas hipótesis, pues además de las lesiones a la honra o la dignidad reconocidas por la Corte Suprema de Justicia desde 1924, se ha condenado a la reparación de este tipo de daño por afectaciones a la fama de una persona 4 , por atentados a las libertades y derechos fundamentales, por la muerte 0 lesión de parientes próximos ${ }^{5} 0$ amigos que demuestren la intensidad de la afectación ${ }^{6}$, por las lesiones personales sufridas por la víctima, sus parientes próximos y padres de crianza $^{7}$, e incluso, por los menoscabos sufridos por personas jurídicas ${ }^{8}$, además se ha previsto el resarcimiento de estos daños en el ámbito contractual $^{9}$.

2 La jurisprudencia francesa consideró hasta 1961 con la providencia del Consejo de Estado del 24 de noviembre del mismo año LETISSERAND-, que las lágrimas nunca se amonedan (les larmes ne se monnayent point) y por consiguiente se reusaba a reparar el daño causado por el dolor moral.

3 CSJ, Civil, 22 Ago.1924, T. Nannetti GJ: T XXI.

4 CSJ, Sala de Negocios Generales, 20 Nov. 1933, E. Becerra GJ: T. XXXIX.

5 Presunción del dolor que sufren los parientes próximos de una víctima, de acuerdo con CSJ, Civil, 28 Oct.1942, A. Cardoso.

6 CSJ, Civil, 13 May. 1988, A. Bonivento; y CSJ, Sala de Negocios Generales 12 Mar.1937, P. Gómez.

7 CE3. 26 Mar. 2008, Exp. 18846. E. Gil.

8 Al efecto, el Consejo de Estado en Sentencia del 20 de agosto de 1993, expediente 7881 con ponencia de Daniel Suárez Hernández abre la posibilidad de resarcir otro tipo de daño moral propio de la persona jurídica que no sea el dolor o aflicción, como podría ser la afectación del buen nombre. De igual manera, en sentencia del 16 de agosto de 2012, con ponencia de Mauricio Fajardo Gómez, el Consejo de Estado indica que es posible indemnizar daño moral a la persona jurídica siempre y cuando se encuentre fundamentado en el acervo probatorio obrante el expediente.

9 Un primer antecedente jurisprudencial que acepta la posibilidad de un daño moral contractual en Colombia se encuentra en un salvamento de voto de Ricardo Hinestrosa Daza en Sentencia de Casación Civil del 29 de Julio de 1944, sin embargo; la jurisprudencia contenciosa administrativa hoy entiende superado el tema y admite el reconocimiento del daño moral contractual, al respecto se puede consultar Consejo de Estado del 24 de septiembre de 1987, expediente No. 4039. Actor: David Vásquez Caicedo y de la misma corporación, sentencia de la Sección Tercera, Expediente No. 12848 C.P. María Elena Giraldo Gómez. 
El Consejo de Estado ha desarrollado distintas tesis en lo que refiere a la tipología de los daños extrapatrimoniales; así, desde el año 1993 han aparecido en el escenario jurídico otras categorías diferentes al daño moral, como las alteraciones a las condiciones de existencia, el perjuicio fisiológico, el daño a la vida de relación, entre otros, que han tenido como finalidad lograr la reparación integral de la víctima. Sin embargo, estas categorizaciones han sido objeto de múltiples críticas por parte de la doctrina, y además, en el campo del litigio han generado incertidumbre jurídica respecto de los daños inmateriales que eventualmente pueda llegar a reconocer el fallador.

Aunado a lo anterior, y debido a los distintos criterios jurisprudenciales elaborados por el máximo órgano de la jurisdicción contenciosa, especialmente en lo que refiere a la cuantificación de los daños extrapatrimoniales, se presentaron eventos en los cuales, aun siendo similares las circunstancias fácticas y los daños padecidos por las víctimas, se indemnizaron de manera diferente.

En atención a estas consideraciones, el presente artículo plantea el siguiente problema: ¿Cuál ha sido el desarrollo de la tipología y la cuantificación de los daños extrapatrimoniales en la jurisdicción contencioso administrativa, desde el año 2001 -fecha en que el Consejo de Estado abandona la liquidación del daño en gramos oro y opta por la cuantificación en salarios mínimos legales-, hasta el año 2014?

Para resolver el cuestionamiento, se realizó el análisis jurisprudencial de los fallos proferidos por el Consejo de Estado en el periodo objeto de estudio, identificando la tipología y topes indemnizatorios de los daños inmateriales utilizada por dicha corpo- ración. De igual manera, se examinó la doctrina nacional que desarrolla el tema objeto de estudio.

En consecuencia, se reseñará la evolución de la tipología del daño extrapatrimonial en Colombia, se caracterizará la cuantificación de los daños establecidos en determinados momentos históricos por la jurisprudencia del Consejo de Estado para resarcir estos daños, y se analizará los actuales parámetros de cuantificación, fijados por el órgano de cierre de la jurisdicción contencioso administrativa.

\section{CONSIDERACIONES HISTÓRICAS SOBRE LA TIPOLOGÍA Y CUANTIFICACIÓN DEL DAÑO INMATERIAL EN COLOMBIA}

El código civil colombiano de 1887 consagró una norma genérica de responsabilidad (art. 2341) y además, determinó los tipos de daño patrimoniales: daño emergente y lucro cesante (art. 1614). Por otra parte, el reconocimiento de los daños extrapatrimoniales, se generó con la sentencia del caso Villaveces ${ }^{10}$, emitida por la Corte Suprema de Justicia en el año 1922, de la que se pueden destacar dos aspectos relevantes:

(...) que el daño extrapatrimonial fue enunciado en forma genérica (de allí que, naturalmente, se le asimilara al pretium doloris), es decir, sin las clasificaciones de las que sería luego objeto y, en segundo término, que el límite de la determinación del quantum de la indemnización era exclusivamente el arbitrum judicis. (Koteich, 2012:195).

En adelante, para cuantificar el daño moral, la Corte Suprema de Justicia realizó una aplicación analógica del artículo 95 del Código Penal de 1936, estableciendo como tope indemnizatorio de este daño, hasta la suma de dos mil pesos.

10 «El caso fue que el Dr. Villaveces, persona de elevada posición en Bogotá, por la muerte de su esposa, compró una bóveda en el cementerio central y encargó a Italia una lápida de mármol. Por error de empleados del municipio, es decir, de la administración del cementerio, fueron sacados los restos de la señora de Villaveces y arrojados a la fosa común, en consecuencia demandó al municipio, en proceso de responsabilidad. El municipio fue condenado a la indemnización del daño patrimonial por Juzgado y Tribunal, y Villaveces recurrió en casación alegando interpretación errónea por parte del Tribunal de los artículos 2341 y 2356 ; al haberle negado la indemnización del daño no patrimonial, rectius moral; la Corte casó la sentencia y reconoció el derecho de Villaveces a ser resarcido de ese otro daño». F. Hinestrosa (1983:684-685). 
En sentencia del 23 de abril de 1941, la Sala de Negocios Generales de la Corte Suprema de Justicia, clasificó el daño moral de la siguiente manera: i). Daño moral objetivado u objetivo, que perjudica la parte social del patrimonio moral, tales como el honor y la reputación; y ii). Daño moral subjetivado que menoscaba la parte afectiva del patrimonio moral o genera un pretium doloris, es decir, se vulneran los sentimientos, afectos y pensamientos. Clasificación que fue objeto de bastantes críticas por la doctrina, toda vez que el daño objetivado conducía a dobles indemnizaciones al confundirse con el lucro cesante. Así, Hinestrosa (1983) señaló que el «incorrectamente denominado "daño moral objetivado» no es otra cosa que un daño patrimonial en la forma de lucro cesante»; e inclusive Tamayo Jaramillo (2007) afirmó que «tal vez ninguna creación jurisprudencial le haya hecho más daño a nuestro ordenamiento jurídico que la referida a los daños morales objetivados».

Luego, en sentencia del 04 de abril de 1968 la Sala Civil de la Corte Suprema de Justicia, planteó por primera vez el daño a la persona, como una categoría adicional al daño moral, entendido como el detrimento 0 afectación a la libertad, el honor o esfera íntima de la persona, el menoscabo a la integridad mental y física, que se reflejen en una afectación patrimonial. Sin embargo, en el caso concreto no se condenó a la parte demandada por dicho concepto. Esta categoría de daño no fue acogida por la jurisprudencia, posiblemente por ser avanzada para la época.

De esta manera, la Corte Suprema de Justicia continuó con la clasificación de daño moral objetivado y subjetivado, y se refirió al daño moral como único daño inmaterial reduciendo su contenido a las afectaciones de los sentimientos y vida interior. Aclarando que a partir del año 2008 apareció en escena la in- demnización al daño a la «vida de relación», como categoría distinta al daño moral.

Si bien, el Consejo de Estado siguió de cerca los lineamientos jurisprudenciales de la Corte Suprema de Justicia en cuanto a la tipología y cuantificación del daño moral como único daño extrapatrimonial, en sentencia del 9 de febrero de 1978 el órgano de cierre de lo contencioso administrativo, planteó un nuevo parámetro para determinar el quantum indemnizatorio, que consistió en realizar la conversión de los dos mil pesos a su equivalente en gramos oro (1000 gr.), con el fin de brindar a la víctimas una estabilidad con relación al valor adquisitivo de la moneda. Esta propuesta fue incorporada normativamente por el artículo 106 del código penal de 1980.

En sentencia del 6 de Mayo de 1993, la Sección Tercera del Consejo de Estado, admitió la posibilidad de indemnizar el daño a la vida de relación o daño fisiológico; como una categoría distinta al daño moral propiamente dicho, y «entendido como la imposibilidad de la víctima para desarrollar su vida en sociedad, producto del menoscabo a su salud o integridad psicofísica». "Como puede observarse en la categoría se hicieron confluir dos rubros de perjuicios distintos, el perjuicio fisiológico francés y el daño a la vida de relación de origen italiano (este último, en alguna medida equivalente al préjudice d'agrément o perjuicio de agrado francés)» (Koteich, 2012:207-208).

A partir de $1997^{11}$, el Consejo de Estado expuso distintos criterios jurisprudenciales en torno a la procedencia del daño fisiológico como categoría autónoma del daño extrapatrimonial, lo que sirvió de antesala para que en sentencia del 19 de Julio del año 2000, desapareciera definitivamente la expresión perjuicio fisiológico, el cual fue sustituido por un

11 Al efecto, se puede consultar la sentencia del 13 de Julio de 1997, expediente 12.499 en donde se sostiene que el daño fisiológico no tiene una entidad jurídica propia y que por el contrario está conformada por daños materiales y extrapatrimoniales; además señala que el perjuicio fisiológico puede ser genérico, entendido como aquellos que se producen en todas las personas que padecen la lesión, por ejemplo: pérdida de sentidos como la vista, audición y habla; y específico, que se presenta por la incidencia de la lesión en actividades de goce espiritual o placenteras. Por otra parte, en sentencia del 25 de Septiembre de 1997, expediente 10.421 se afirmó que el perjuicio fisiológico existe solo si ha sido capaz de producir un daño a la vida de relación. 
concepto más amplio: daño a la vida de relación, que proviene no solo de las lesiones corporales, sino de cualquier otro hecho.

Así, puede derivarse de una acusación calumniosa o injuriosa, de la discusión del derecho al uso del propio nombre o de la utilización de este por otro, de un sufrimiento intenso (daño moral), o, inclusive, de una afectación al patrimonio "como podría ocurrir en aquellos eventos en que la pérdida económica es tan grave que -al margen del perjuicio material que en sí mismo implica-produce una alteración importante de las posibilidades vitales de las personas». Y puede ser sufrido el daño a la vida de relación tanto por la víctima como las personas cercanas a ellas, entre otras razones, por parentesco 0 amistad (M'Causland. 2008:61).

Con relación a la cuantificación del daño, el Consejo de Estado - nuevamente en procura de salvaguardar los principios de equidad y reparación integral -, en sentencia del 06 de septiembre de 2001 abandonó la unidad de medida de gramos oro y adoptó como nuevo criterio la indemnización en salarios mínimos mensuales legales vigentes (s.m.m.l.v), estableciendo como límite la suma de cien (100) salarios por concepto de perjuicios inmateriales, tope que en todo caso no era de imperativa aplicación para los juzgadores de instancia, quienes efectuaban la liquidación del daño atendiendo las particularidades del caso.

Durante los años 2007 y 2008 el máximo órgano de lo contencioso administrativo formuló una nueva tipología de daño inmaterial: alteración a las condiciones de existencia, que comprendía la relación de la víctima con el mundo exterior, y los cambios radicales en sus condiciones de vida. De este modo, abandonó la denominación del daño a la vida de relación, por cuanto esta nueva categoría ofrecía mayor flexibilidad para indemnizar, no solo los daños ocasionados a la integridad física y/o psíquica, sino cualquier vulneración de bienes, derechos o intereses diferentes a los señalados, es decir, aquellas prerrogativas que sobrepasan la esfera de lo corporal del sujeto afectado, tales como la honra, el buen nombre, el daño al proyecto de vida, entre otras ${ }^{12}$.

La conceptualización del Consejo de Estado respecto a esta tipología del daño, que suponía una modificación de las condiciones habituales de vida, en modo «superlativo, en aspectos significativos de la normalidad que el individuo llevaba», evidenciando "un trastocamiento de los roles cotidianos», generó que la doctrina afirmara que tan solo se efectuó un cambio nominal del antiguo daño a la vida de relación propuesto en 1993 (M`Causland, 2008:64).

Luego, en sentencias gemelas proferidas por la Sala Plena de la Sección Tercera del Consejo de Estado, con fecha del 14 de septiembre del 2011, se propone la tipología del daño a la salud que desplazó las demás categorías del daño extrapatrimonial, pues a juicio de la Corporación «cuando la lesión antijurídica tiene su génesis en una afectación negativa del estado de salud, los únicos perjuicios inmateriales que hay lugar a reconocer son el daño moral y el daño a la salud ${ }^{13}$. Este daño tuvo como finalidad resarcir la pérdida, alteración anatómica 0 funcional del derecho a la salud y a la integridad corporal, y comprende toda la esfera psicofísica de la víctima; tiene dos componentes: uno estático, que constituye la medida de la lesión que se indemniza igual para las víctimas, y otro dinámico, relacionado con las condiciones personalísimas de la víctima en particular; se estableció como tope indemnizatorio la suma de cuatrocientos (400) salarios mínimos legales mensuales vigentes.

Además del daño a la salud, las sentencias gemelas plantean otra categoría, bastante amplia, denominada daños a cualquier otro bien, derecho o interés legítimo constitucional, jurídicamente tutelado, que no esté comprendido dentro del concepto del daño a la salud y que amerite una indemnización, tales como el derecho al buen 
nombre al honor y a la honra, el derecho a tener una familia, entre otros.

De esta manera, a partir de dichas sentencias y hasta la fecha, se reconocen en la jurisdicción contenciosa administrativa tres categorías de daños extrapatrimoniales: i). El perjuicio moral o pretium doloris; propiamente dicho, que comprende las afectaciones causadas por las ofensas y actos en contra de los derechos personalísimos, que causan dolor 0 molestia; ii). El daño a la salud (perjuicio fisiológico o biológico); como categoría autónoma que resulta de las lesiones que recaen sobre la esfera cognoscitiva, integridad corporal, psicológica, sexual, estética entre otros; y iii). El daño inmaterial por afectación relevante a bienes o derechos convencional y constitucionalmente amparados.

\section{SENTENCIAS DE UNIFICACIÓN DEL 28 DE AGOSTO DE 2014 PROFERIDAS POR LA SALA PLENA DE LA SECCIÓN TERCERA DEL CONSEJO DE ESTADO}

Tal como se ha podido observar, al interior del Consejo de Estado la tipología y cuantificación del daño extrapatrimonial, ha sido objeto de una constante evolución; a lo anterior habría que añadir que en el 2011 se propuso un nuevo parámetro de reparación, distinto al arbitrio judicial, denominado: Test de proporcionalidad, ${ }^{14}$ el cual, consistía en unas tablas que contenían topes indemnizatorios atendiendo al parentesco de las víctimas y al grado de convivencia entre ellas, de conformidad a las pruebas allegadas al proceso, con la finalidad de evitar que el juzgador desarrollara discursos que generen desigualdades al liquidar el perjuicio, por lo que se propuso unos estándares mínimos objetivos para realizar una tasación proporcional, ponderada y adecuada de los perjuicios morales, sin que se constituya en tarifa judicial 0 , se pretenda el establecimiento de una tarifa legal.
Este escenario motivó a que la Sección Tercera del Consejo de Estado expidiera el 28 de agosto del 2014, ocho (8) sentencias de unificación de criterios de reconocimiento y tasación de esta clase de perjuicios, buscando con ello garantizar los principios de igualdad, reparación integral y seguridad jurídica. De esta manera, se diseñaron tres escenarios para la reparación del daño moral: i). En caso de muerte; ii). Lesiones personales; y iii). En eventos de privación injusta de la libertad.

En cuanto al daño a la salud se establecen unos topes indemnizatorios atendiendo el porcentaje de gravedad de la lesión, y las consecuencias o alteraciones a nivel de comportamiento de la víctima en su entorno social que agraven su condición. Por otra parte, se determinó la procedencia del daño inmaterial por afectación relevante a bienes o derechos convencional y constitucionalmente amparados, en donde prevalecen medidas de reparación integral no pecuniarias y excepcionalmente habrá lugar a una indemnización de hasta cien (100) salarios mínimos.

\subsection{Reparación del daño moral}

Este concepto atiende a los sentimientos de dolor, tristeza, congoja, temor, zozobra entre otros, que conmocionan a las víctimas directas e indirectas del daño antijurídico. Como regla general, se establece un tope indemnizatorio de hasta cien (100) salarios mínimos; sin embargo, en los eventos de graves violaciones a los derechos humanos, o cuando se acredite una mayor intensidad o gravedad del daño, el fallador, mediante sentencia debidamente motivada podrá reconocer un quantum superior al señalado.

\subsubsection{En eventos de muerte}

Tiene como fundamento el dolor que padece una persona por causa de la muerte de otra, el cual se agrava dependiendo de la proximidad entre las víctimas. Para lo cual, en la tabla que se expone a continuación se define el nivel de cercanía de las

14 Esto ha sido una propuesta del magistrado Jaime Orlando Santofimio Gamboa, en salvamento de voto realizado en sentencia del 22 de junio del 2011, rad. 20416 y en la aclaración de voto de sentencia del 27 de julio de 2011, rad. 20898. Postura que se consolida en sentencia del 31 de agosto de 2011 expediente: 250001-23-31000-1997-08938-01, y que se reitera en sentencia del 01 de febrero de 2012 rad. 21567. 
víctimas, lo que se debe acreditar y su correspondiente quantum. Tabla 1.

\subsubsection{En caso de lesiones corporales}

En este escenario se tiene en cuenta el dolor 0 padecimiento que se causa a la víctima directa, sus familiares y las demás personas cercanas a esta, derivado de un daño a la integridad física, por lo que la indemnización se realiza teniendo en cuenta la magnitud de la lesión que se logre acreditar en el proceso; para lo cual se manejan seis (6) rangos indemnizatorios, que se exponen en la tabla 2.

\subsubsection{En eventos de privación injusta de la libertad}

Sobre este punto, ya existían antecedentes que intentaban estandarizar los criterios indemnizatorios del daño moral. De esta manera, el Consejo de Estado, en sentencia de unificación del 28 de agosto de 2014, complementa y consolida los parámetros que ya había adoptado en este tipo de casos, para lo cual se tendrá en cuenta el tiempo durante el cual la victima directa ha estado privada de su libertad injustamente, y el grado parentesco y cercanía con las víctimas indirectas, establecido en la tabla 3.

\subsubsection{Regla de excepción para todos los casos de daños morales}

El Consejo de Estado señaló que en casos de graves violaciones a los derechos humanos, los jueces podrán apartarse de los topes señalados, siempre y cuando se encuentren acreditadas circunstancias de mayor intensidad del daño, para lo cual el fallador deberá motivar su decisión; en todo caso, la indemnización por este concepto no podrá superar el triple de los montos establecidos, es decir, hasta 300 s.m.I.m.v.

\subsection{Daño a la salud}

Retomando la jurisprudencia del año $2011^{15}$, el Consejo de Estado consolida el concepto del daño a la salud, entendido como «la afectación corporal o sicofísica relativa a los aspectos o componentes

Tabla ${ }^{16}$. Regla general de la reparación del daño moral en caso de muerte.

\begin{tabular}{|c|c|c|c|c|c|}
\hline & Nivel 1 & Nivel 2 & Nivel 3 & Nivel 4 & Nivel 5 \\
\hline & $\begin{array}{l}\text { Relación entre } \\
\text { padres, hijos, } \\
\text { suegros, esposos } \\
\text { o compañeros } \\
\text { permanentes y la } \\
\text { victima directa. }\end{array}$ & $\begin{array}{l}\text { Relación entre } \\
\text { abuelos, } \\
\text { hermanos, } \\
\text { cuñados o nietos y } \\
\text { la victima directa. }\end{array}$ & $\begin{array}{c}\text { Relación entre } \\
\text { bisabuelos, tíos, } \\
\text { sobrinos o } \\
\text { bisnietos y la } \\
\text { victima directa. }\end{array}$ & $\begin{array}{c}\text { Relación entre } \\
\text { primos, } \\
\left(3^{\circ} \text { grado de }\right. \\
\text { consanguinidad } \\
\text { o civil) y la } \\
\text { victima directa. }\end{array}$ & $\begin{array}{c}\text { Relación afectivas } \\
\text { no familiares - } \\
\text { terceros } \\
\text { damnificados y la } \\
\text { victima directa. }\end{array}$ \\
\hline $\begin{array}{l}\text { Aspectos que } \\
\text { se deben } \\
\text { acreditar. }\end{array}$ & $\begin{array}{l}\text { Prueba del estado } \\
\text { civil o de la } \\
\text { convivencia de los } \\
\text { compañeros }\end{array}$ & $\begin{array}{l}\text { Prueba del estado } \\
\text { civil o de la } \\
\text { convivencia de los } \\
\text { compañeros }\end{array}$ & $\begin{array}{c}\text { Prueba del } \\
\text { estado civil, de la } \\
\text { convivencia de } \\
\text { los compañeros y } \\
\text { de la relación } \\
\text { afectiva } \\
\end{array}$ & $\begin{array}{c}\text { Prueba del } \\
\text { estado civil o de } \\
\text { la convivencia de } \\
\text { los compañeros, } \\
\text { y de la relación } \\
\text { afectiva }\end{array}$ & $\begin{array}{l}\text { Prueba de la } \\
\text { relación afectiva }\end{array}$ \\
\hline $\begin{array}{l}\text { Equivalencia } \\
\text { en salarios } \\
\text { mínimos }\end{array}$ & 100 & 50 & 35 & 25 & 15 \\
\hline
\end{tabular}

15 CE3. 14 Sept. 2011, exp.19.031, E. Gil.

16 CE3. 28 Ago. 2014, exp. 26251, J. Santofimio y; CE3, 28 Ago. 2014, exp. 27709, C. Zambrano. 
Tabla $2^{17}$. Regla general de la reparación del daño moral en caso de lesiones.

\begin{tabular}{|c|c|c|c|c|c|}
\hline & Nivel 1 & Nivel 2 & Nivel 3 & Nivel 4 & Nivel 5 \\
\hline $\begin{array}{c}\text { Gravedad de } \\
\text { la lesión. }\end{array}$ & $\begin{array}{c}\text { Relaciones } \\
\text { afectivas } \\
\text { conyugales y } \\
\text { paterno- filiales }\end{array}$ & $\begin{array}{l}\text { Relación afectiva } \\
\text { del } 2^{\circ} \text { grado de } \\
\text { consanguinidad } \\
\text { civil (abuelos, } \\
\text { hermanos, nietos) }\end{array}$ & $\begin{array}{l}\text { Relación afectiva } \\
\text { del } 3^{\circ} \text { grado de } \\
\text { consanguinidad } \\
\text { o civil }\end{array}$ & $\begin{array}{c}\text { Relación afectiva } \\
\text { del } 3^{\circ} \text { grado de } \\
\text { consanguinidad } \\
\text { o civil }\end{array}$ & $\begin{array}{c}\text { Relación afectivas } \\
\text { no familiares - } \\
\text { terceros } \\
\text { damnificados }\end{array}$ \\
\hline & S.M.L.M.V & S.M.L.M.V & S.M.L.M.V & S.M.L.M.V & S.M.L.M.V \\
\hline $\begin{array}{c}\text { Igual } 0 \\
\text { superior al } \\
50 \%\end{array}$ & 100 & 50 & 35 & 25 & 15 \\
\hline $\begin{array}{c}\text { Igual o } \\
\text { superior al } \\
40 \% \text { e } \\
\text { inferior al } \\
50 \% \\
\end{array}$ & 80 & 40 & 28 & 20 & 12 \\
\hline $\begin{array}{c}\text { Igual o } \\
\text { superior al } \\
30 \% \text { e } \\
\text { inferior al } \\
40 \% \\
\end{array}$ & 60 & 30 & 21 & 15 & 9 \\
\hline $\begin{array}{c}\text { Igual o } \\
\text { superior al } \\
20 \% \text { e } \\
\text { inferior al } \\
30 \% \\
\end{array}$ & 40 & 20 & 14 & 10 & 6 \\
\hline $\begin{array}{c}\text { Igual o } \\
\text { superior al } \\
10 \% \text { e } \\
\text { inferior al } \\
20 \% \\
\end{array}$ & 20 & 10 & 7 & 5 & 3 \\
\hline $\begin{array}{c}\text { Igual o } \\
\text { superior al } \\
1 \% \text { e inferior } \\
\text { al } 10 \%\end{array}$ & 10 & 5 & 3,5 & 2,5 & 1,5 \\
\hline
\end{tabular}

funcionales, biológicos y síquicos de la persona, la cual se refleja en las alteraciones a su nivel de comportamiento y desempeño dentro del entorno social y cultural que agravan la condición de la víctima» ${ }^{18}$; es decir, se indemniza:
1. El daño considerado en sí mismo, o daño evento, que puede valorarse objetivamente, teniendo en cuenta las siguientes variables: i) La pérdida 0 anormalidad de la estructura o función psicológica, fisiológica o anatómica, temporal o

17 CE3. 28 Ago. 2014, exp. 31172, O. Valle de la Hoz

18 CE3. 28 Ago. 2014, exp. 31170, E. Gil. 
Tabla $3^{19}$. Regla general de la reparación del daño moral en caso de privación injusta de la libertad.

\begin{tabular}{|c|c|c|c|c|c|}
\hline & Nivel 1 & Nivel 2 & Nivel 3 & Nivel 4 & Nivel 5 \\
\hline $\begin{array}{l}\text { Término } \\
\text { de la } \\
\text { privación } \\
\text { injusta en } \\
\text { meses } \\
\end{array}$ & $\begin{array}{l}\text { Víctima directa, conyugue o } \\
\text { compañero (a) permanente y } \\
\text { parientes en } 1^{\circ} \text { de } \\
\text { consanguinidad }\end{array}$ & $\begin{array}{l}\text { Parientes en el } \\
2^{\circ} \text { de } \\
\text { consanguinidad }\end{array}$ & $\begin{array}{l}\text { Parientes en el } \\
3^{\circ} \text { de } \\
\text { consanguinidad }\end{array}$ & $\begin{array}{c}\text { Parientes en } \\
\text { el } 4^{\circ} \text { de } \\
\text { consanguinidad } \\
\text { y afines hasta } \\
\text { el } 2^{\circ} \text { grado. }\end{array}$ & $\begin{array}{c}\text { Terceros } \\
\text { damnificados. }\end{array}$ \\
\hline $\begin{array}{l}\text { Superior a } \\
18 \text { meses }\end{array}$ & 100 & 50 & 35 & 25 & 15 \\
\hline $\begin{array}{c}\text { Superior a } \\
12 \mathrm{e} \\
\text { inferior a } \\
18 \\
\end{array}$ & 90 & 45 & 31,5 & 22,5 & 13,5 \\
\hline $\begin{array}{l}\text { Superior a } \\
9 \text { e inferior } \\
\text { a } 12 \\
\end{array}$ & 80 & 40 & 28 & 22,5 & 12 \\
\hline $\begin{array}{l}\text { Superior a } \\
6 \text { e inferior } \\
\text { a } 9 \\
\end{array}$ & 70 & 35 & 24,5 & 20 & 10,5 \\
\hline $\begin{array}{l}\text { Superior a } \\
3 \text { e inferior } \\
\text { a } 6 \\
\end{array}$ & 50 & 25 & 17,5 & 12,5 & 7,5 \\
\hline $\begin{array}{l}\text { Superior a } \\
1 \text { e inferior } \\
\text { a } 3 \\
\end{array}$ & 35 & 17,5 & 12,25 & 8,75 & 5,25 \\
\hline $\begin{array}{c}\text { Igual e } \\
\text { inferior a } 1\end{array}$ & 15 & 7,5 & 5,25 & 3,75 & 2,25 \\
\hline
\end{tabular}

permanente; ii). La anomalía, defecto o pérdida producida en un miembro, órgano, tejido u otra estructura mental o corporal; iii). La exteriorización de un estado patológico que refleje perturbaciones a nivel de un órgano; iv). La reversibilidad o irreversibilidad de la patología; v). La edad y; vi). El sexo.

2. Las consecuencias del daño, que tienen una connotación subjetiva, tales como: i). La restricción 0 ausencia de la capacidad para realizar una actividad normal; ii). Los excesos en el desempeño y comportamiento dentro de una actividad de rutina; iii). Las limitaciones o impedimentos para el desempeño de un rol determinado; iv). Los factores sociales, culturales u ocupacionales; y vi). Las que tengan relación con la afectación de bienes placenteros, lúdicos y agradables de la víctima.

El daño a la salud, se otorga exclusivamente a la víctima directa, estableciendo como regla general una indemnización de hasta cien (100) salarios mínimos legales mensuales vigentes, aunque excepcionalmente, es decir, en eventos en los cuales se pruebe una mayor intensidad y gravedad del 
daño, podrá ser reconocidos hasta los cuatrocientos (400) salarios mínimos, decisión que deberá ser motivada y proporcional, aplicando las variables expuestas. Tabla 4.

\subsection{Daños por afectación relevante a bienes o de- rechos convencional o constitucionalmente amparados}

En recientes pronunciamientos, el Consejo de Estado se ha fundamentado en la Convención Americana de Derechos Humanos y la interpretación que de ella ha realizado la Corte Interamericana de Derechos Humanos para reparar los daños originados por graves violaciones a los Derechos Humanos, fenómeno que se ha denominado Control de Convencionalidad ${ }^{20}$.

En ese orden de ideas, en las sentencias de unificación se crea una macro categoría denominada: "Daño Inmaterial por afectación relevante a bienes o derechos convencional y constitucionalmente amparados», el reconocimiento de estos daños procede a petición de las partes 0 de manera oficiosa, siempre y cuando se pruebe dentro del expediente su ocurrencia, y sea necesaria su reparación. Como se puede apreciar, se repararían la vulneración a derechos que tienen fuentes normativas diversas, es decir, derechos constitucionales o convencionales.
La finalidad de la reparación de este tipo de daño, está orientado a restaurar los derechos de las víctimas de manera individual o colectiva, en procura de evitar la repetición de casos de violaciones a estos derechos y además, propende por la realización efectiva de la igualdad sustancial.

Para el Consejo de Estado, en esta macro-categoría priman las medidas de reparación no pecuniarias, que tendrán en cuenta la magnitud de los hechos, con el propósito de reconocer la dignidad de las víctimas, reprobar las violaciones de los Derechos Humanos y concretar la garantía de verdad, justicia, reparación, no repetición y las demás definidas por el derecho internacional.

En consecuencia, y atendiendo los principios de «Van Boven/Bassiouni», adoptados por la Asamblea General de las Naciones Unidas en el 2005, como medidas de reparación no pecuniarias, el juez podrá decretar:

i). Garantías de no repetición: Dirigidas especialmente a que los hechos que causaron los daños no vuelvan a ocurrir. Dentro de estas medidas se pueden citar como ejemplo, las órdenes judiciales concernientes en la enseñanza y observancia de las normas de Derechos Humanos y Derecho Internacional Humanitario a todos los

Tabla 421. Regla General de Reparación del Daño a la Salud.

\begin{tabular}{c|c}
\hline Gravedad de la lesión & Víctima directa (s.m.I.m.v.) \\
\hline Igual o superior al $50 \%$ & 100 \\
\hline Igual o superior al $40 \%$ e inferior al $50 \%$ & 80 \\
\hline Igual o superior al $30 \%$ e inferior al $40 \%$ & 60 \\
\hline Igual o superior al $20 \%$ e inferior al $30 \%$ & 40 \\
\hline Igual o superior al $10 \%$ e inferior al $20 \%$ & 20 \\
\hline Igual o superior al $1 \%$ e inferior al $10 \%$ & 10 \\
\hline
\end{tabular}

20 Un ejemplo de la aplicación del Control de Convencionalidad para la reparación de daños materiales por violación a los Derechos Humanos, lo encontramos en sentencia del 27 de septiembre 2013, rad. 19939 Consejera Ponente: Stella Conto Díaz Del Castillo, actora Fabiola Lalinde De Lalinde y Otros contra la Nación Ministerio De Defensa - Ejército Nacional.

21 CE3, 28 Ago. 2014, exp. 28832, D. Rojas. 
sectores de la sociedad, especialmente a las fuerzas militares y demás cuerpos de seguridad; así como también, la garantía de que todos los procedimientos (civiles y militares) se ajusten a las normas internacionales con el debido respeto de las garantías procesales, la equidad y la imparcialidad.

ii). Satisfacción: Siempre que se estime pertinente, se podrán ordenar acciones tendientes a garantizar los derechos a la verdad, justicia y memoria de las víctimas; a titulo ilustrativo se pueden mencionar las ordenes dirigidas a la verificación de los hechos, la revelación pública y completa de la verdad, la búsqueda los desaparecidos, la identidad de quienes fueron asesinados y la ayuda para recuperarlos, y despedirlos atendiendo las prácticas culturales de su familia y/o comunidad; la aplicación de sanciones judiciales o administrativas a los responsables de las violaciones, el ofrecimiento de disculpas públicas, así como los demás actos que conmemoren a las víctimas (elaboración de monumentos, placas, creación de becas 0 establecimientos educativos como homenaje póstumo) (Noguera, 2010).

iii). Rehabilitación: Son medidas dirigidas a recuperar la integridad psicofísica de las víctimas, es decir, incluyen la atención médica, psicológica, y los servicios jurídicos y sociales para el restablecimiento de los derechos vulnerados.

A voces del Consejo de Estado, estas medidas reparatorias no pecuniarias se ordenaran a favor de la víctima directa y a su núcleo familiar más cercano. Sin embargo, en casos excepcionales, es decir, cuando las medidas descritas anteriormente no logren consolidar la reparación integral de las víctimas, se podrá reconocer una indemnización, única y exclusivamente a la víctima directa del daño, siempre y cuando esta no se haya reconocido por el concepto del daño a la salud. Para tal efecto, se establece como tope indemnizatorio la suma de hasta cien (100) salarios mínimos legales mensuales vigentes.
Con el fin de evitar que la víctima obtenga una doble reparación por los daños causados, el Consejo de Estado ha señalado:

(...) el juez debe verificar los siguientes aspectos: a) que se trate de una vulneración a un derecho constitutiva de daño; b) que sea relevante; c) que las medidas de reparación no estén comprendidas dentro de los perjuicios materiales e inmateriales ya reconocidos y; d) que las medidas de reparación sean correlativas pertinentes y adecuadas al daño generado a los derechos convencionales y constitucionales. (Exp. 32988).

\section{CONCLUSIONES}

El desarrollo de la tipología de los daños extrapatrimoniales en Colombia, y en especial en la jurisdicción contencioso administrativa, no ha sido en tema pacífico; tal como se expuso en el escrito, se evidenció que en el escenario jurisprudencial han aparecido distintas categorías, tales como el daño fisiológico, el perjuicio de agrado, la alteración a las condiciones de existencia, entre otras, -que hoy quedaron eliminadas por las sentencias de unificación- como un ejercicio que ha realizado el Consejo de Estado para obtener una reparación integral de las víctimas -al margen de todas la discusiones filosóficas que suscita este tema-.

Con el fin de lograr una unificación en la reparación de los daños extrapatrimoniales, la jurisdicción contencioso administrativa, ha establecido las siguientes tipologías: a) el daño moral, o «pretium doloris»; b) el daño a la salud y; c) los daños a derechos o bienes convencional y constitucionalmente protegidos. Se considera que esta última categoría no es afortunada, por las siguientes razones: En primer lugar, no existe una frontera o límite que permita diferenciarlo de las otras categorías de indemnización patrimonial o extrapatrimonial, debido a la amplitud en el «nomen iuris», puesto que permitiría que cualquier derecho consagrado en el catalogo constitucional y convencional sea objeto de indemnización adicional, es decir, se podría correr el riesgo de estar indemnizando un mismo daño bajo dos rubros distintos. 
Al margen de las críticas que se generan en la clasificación y cuantificación de los daños extrapatrimoniales, se aplaude y ve con buenos ojos la propuesta consagrada en las sentencias de unificación, puesto que se busca obtener una coherencia en la jurisprudencia de la alta corte y los jueces de instancia, en procura de una igualdad sustancial, además la practicidad de las tablas permitirá que la labor del juez sea más fácil.

En cuanto a la cuantificación, es afortunada la tasación en salarios mínimos legales mensuales, pues permite que se respete el valor adquisitivo, situación que no se lograba consolidar con las indemnizaciones realizadas en gramos oro. Por otra parte, los topes máximos se han mantenido, en lo que refiere al daño moral y el daño a la salud.

Se resalta que a pesar de los topes y criterios establecidos por el Consejo de Estado, se evita que se caiga en un desequilibrio al momento de reparar un daño, puesto que se le deja un margen de autonomía para que el juez, en virtud del «arbitrio judicial», proceda a realizar la reparación atendiendo las particularidades de cada caso.

Se espera que la jurisdicción administrativa y la jurisdicción ordinaria establezcan un diálogo común en materia de reparación de los daños extrapatrimoniales, con el fin de que se logren eliminar las diferencias que actualmente subsisten entre una y otra con ocasión a la tipología y cuantificación de estos daños.

\section{REFERENCIAS BIBLIOGRÁFICAS}

- Barragán Romero, G. (1995). Elementos del daño moral. Guayaquil, Ecuador: Edino.

- Barrientos, M. (2008). Del daño moral al daño extrapatrimonial: la superación del pretium doloris. Revista chilena de derecho, 35 ( $\left.{ }^{\circ} 1\right)$, pp. 85-106.

- Bernal Pulido, C. (2007). El derecho de los derechos. Análisis del test de proporcionalidad. Bogotá, Colombia: Universidad Externado de Colombia.
- Brutau, J. (2004). Arbitrio judicial. Nueva enciclopedia jurídica seix, voz. España.

- Cortes, E. (2006). Constitución y responsabilidad civil: Una relación ambivalente. Revista de derecho privado. ( $\left.N^{\circ} 11\right)$ pp. 171-179

- Díez Schwerter, J. (2005). La resarcibilidad del daño no patrimonial en Chile, Colombia, Ecuador y El Salvador. Del modelo de Bello a nuestros días. Revista de derecho privado. ( $\left.{ }^{\circ} 09\right)$ pp. 177-203.

- Díez Schwerter, J. (2006). La resarcibilidad del daño no patrimonial en América latina: una visión histórica comparativa. Anales de la Facultad de Derecho de la Pontificia Universidad Católica de Chile, N 1, pp. 165-192.

- Fernández Rodríguez, T. (2005). Del arbitrio y de la arbitrariedad judicial. Madrid, España: Editorial lustel.

- Henao, J. (2007). El daño. Análisis comparativo de la responsabilidad extracontractual del Estado en el derecho colombiano y francés. Bogotá, Colombia: Universidad Externado de Colombia.

- Hinestrosa, F. (2000). Devenir del derecho de daños. Editorial Universidad Externado de Colombia. ( $\left.\mathrm{N}^{\circ} 10\right)$ pp. 17.

- Hinestrosa, F. Escritos varios, (1983). Bogotá, Colombia: Umaña Trujillo impresores.

- Koteich Kathib, M. (2008). La reparación del daño como mecanismo de tutela de la persona. Bogotá: Universidad Externado de Colombia.

- Koteich Kathib, M. (2009). La Indemnización Del Daño Extrapatrimonial a La Persona, ¿Un Retorno a La Pena Privada Del Derecho Romano? En Seminario para la Armonización del Derecho Privado en América Latina. Bogotá. Universidad Externado de Colombia.

- Koteich Kathib, M. La Dispersión del daño extrapatrimonial en Italia: Daño biológico vs. Daño existencial. Revista de Derecho Privado, (N¹5), pp. 145-162.

- Koteich Khatib, M. (2006). El daño extrapatrimonial, las categorías y su resarcimiento Italia y Colombia. Vicisitudes de dos experiencias. Revista De Derecho Privado. (N¹0). pp.161- 195. 
- León Mazeaud, Henri Mazeaud \& André Tunc. (1961).Tratado teórico y práctico de la responsabilidad civil delictual y extracontractual. Buenos Aires, Argentina: Ediciones Jurídicas Europa y América.

- M'causland Sánchez, M. (2008). Tipología y reparación del daño no patrimonial. Situación en Iberoámerica y en la jurisprudencia de la Corte Interamericana de Derechos Humanos. Bogotá, Colombia: Universidad Externado de Colombia.

- $\quad$ Noguera, H. (2010). Consejo de Estado vs. Corte Interamericana de Derechos Humanos en materia de reparaciones. Verbas luris. (vol. 24). pp. 99-119

- Navia, F. (2006). Del daño moral al daño fisiológico. Bogotá, Colombia. Universidad Externado de Colombia.

- Navia, F. (2007). Daño Moral, daño fisiológico y daño en la vida de relación en Colombia. Revista de Derecho Privado. (N¹2-13). pp.289-305.

- Nieto, García. A. (2000). El arbitrio judicial. Barcelona, España: Editorial Ariel.

- Rodríguez, R. (2005). La transmisión y prueba del derecho a la indemnización por daño moral. Bogota: Editorial Universitas.

- Tamayo, Jaramillo. J. (2007). De la responsabilidad civil. Tomo IV de los perjuicios y su indemnización. Bogotá. Editorial Legis.

\section{REFERENCIAS JURISPRUDENCIALES}

\section{Corte Suprema de Justicia:}

CSJ Sala de Casación Civil; 22 Ago. 1924; T. Nannetti; GJ: TXXI.

CSJ Negocios Generales; 20 Nov. 1933; E. Becerra; GJ:T. XXXIX.

CSJ Negocios Generales; 12 de Mar. 1937; P. Gómez.

CSJ Sala de Casación Civil; 23 Abr. 1941, A. Cardozo. G.J: T. XII

CSJ Sala de Casación Civil; 13 de May. 1988; A. Bonivento.

\section{Consejo de Estado:}

CE. 24 sept. 1987, e. 4039. Actor: David Vásquez Caicedo.
CE. 27 Ago. 1992, e. 6221. J. Montes. CE. 20 Ago. 1993, e. 7881, D. Suárez. CE3. 09 Oct. 1997, e. 10421, R. Hoyos. CE. 10 Sep. 1998, e. 12009, D. Suárez. CE. 19 Jul. 2000, e. 11842. A. Eduardo. CE. 27 Jul.2000, e. 12788, R. Hoyos. CE. 14 Jul. 2004, e. 143118. A. Hernández. CE. 14 Abr. 2005, e. 13814. G. Rodríguez. CE. 10 Nov. 2005, e. 23420. A. Hernández. CE. 5 Dic. 2005, e. 13339. A. Hernández. CE. 10 Ago. 2005, e. 16205. M. Giraldo. CE. 11 May. 2006, e.15626. R. Saavedra. CE. 1 Mar. 2006, e. 14408. A. Hernández. CE3. 15 Ago. 2007. AG-385.

CE. 20 Sep. 2007, e. 14272. M. Fajardo. CE. 19 Oct. 2007, e. 29273. E. Gil. CE3. 26 Mar. 2008, e. 18846. E. Gil. CE3. 28 Ene. 2009, e. 30340. E. Gil. CE3. 17 Mar. 2010, e. 18799. R. Correa. CE. 14 Sept. 2011, e. 19.031. E. Gil CE. 19 Nov. 2012, e. 23343. E. Gil. CE. 27 Feb. 2013, e. 25334. J. Santofimio. CE. 13 Jun. 2013, e. 20771. J. Santofimio. CE. 13 Jun. 2013, e. 26800. J. Santofimio. CE. 30 Ene. 2013, e. 24530. E. Gil.

\section{WEB GRAFÍA}

- Álvarez Pérez, A. \& Martínez Rodríguez, P. (AÑO). Estado actual de la jurisprudencia en relación con los perjuicios inmateriales. Disponible en: http://www.iarce.com/conclusiones/ Revista\%20No.\%2020.pdf. Consultado Agosto de 2013.

- Gil Botero, E. (2012). Instituciones del daño a la salud. Disponible en: http://www.revista pielagus. com/adiocinal/file/INSTRUCCIONES\% 20A\%20LOS20AUTORES\%20final\%202.pdf. Consultado, Julio de 2013.

- Velásquez Posada, O. (2012). Itinerario jurisprudencial del daño moral en Colombia. Disponible en: http://www.derechodelseguro. com.ar/Octubre_27_2012_ITINERARIO_ MORAL_COLOMBIA_ObdulioVelasquez.pdf: Consultado Noviembre 2013. 